\title{
Política de Habitação
}

\section{Augusto LuIz DupRat}

\author{
"As idéias, as mais generosas, que não estejam sòlidamente ampa- \\ radas por "Sua Majestade o Dinheiro" estão, de antemão, fadadas a um \\ lamentável fracasso." (ANDRÉ FOURGEAUD, op. cit.)
}

IV.

\section{FINANCIAMENTO}

A

construção da casa, - o melhor dos investim: ntos -, sempre foi um privilégio dos bafejados pela fortuna, em maior ou menor escala. Com o decorrer dos tempos, aumento de população do mundo, concentração humana nas cidades e, scbretudo, o valor econômico da vida humane, apresentou-se o problema em tôda a sua plenitude, esbarrando, sempre, sua solução, no problema econômico.

Qualquer que seja a finalidade de um investimento, para que tenha sucesso, é necessário ser feito de tal modo que, além de ser útil ao financiador e ao financiado, satisfaça as condięões seguintes:

$$
\begin{aligned}
& 2-1 \text { - Garantia } \\
& 2-2 \text { - Rentabilidade } \\
& 2-3 \text { - Exequibilidade } \\
& 2-4 \text { - Finalidade Social. }
\end{aligned}
$$

A garantia será dada pela natureza do negócio; no caso em apreço, pela boa estabilidade da construção, seu bom acabamento, sua durabilidade, sua situação, forma e dimensões do terreno.

A rentabilidade será garantida pela utilização, isto é, pelas possibilidades de produzir renda, conseqüente à maior ou menor procura.

A exequibilidade, - conseqüência da utilização - é representada pelas facilidades que possa apresentar o negócio, de liquidação imediata.

A finalidade social, não só pelas vantagens que possa oferecer à casa própria, como também pelo mudo como tenha sido efetuada a transação, a fim de que não constitua um fardo para o financiado...

Como se vê, as quatro condições acima, estão tão intímamente ligadas que é, mesmo, difícil definir cada uma de por si, sem que sejamos obrigados a aludir às outras. 
No caso em estudo, há três categorias de indivíduos a serem atendidcs: os que econômicamente estão em condições de ter caso, isto é, comprá-la, quer diretamente, quer por meio de financiamento, os que só tem condições para alugar a casa e aqueles que não estão em condições nem de comprar nem de alugar, dentro da atual conjuntura. Apesar de não terem condições senão para alugar a casa ou não terem nem mesmo, esta condição, não deixam êstes indivíduos - de terem direito à casa, de vez que contribuem, com seu trabalho cotidianc, para o bem estar da coletividade.

Como já dissemos, proporcionar a casa, criando dificuldades ao financiado para o seu pagamento, deixa de ser um bom negócio para ambas as partes, financiador e financiado.

O financiador quer o máximo de garantias e $c$ máximo de rendimentos; de um modo geral, o financiado oferece poucas garantias e necessita de um mínimo de juros. Ao primeiro, interessa um investimento a prazo curto, ao segundo a prazo longo. Equacionado assim, o problema, parece, à primeira vista, insolúvel, no entanto não o é, se nos valermos do auto-financiamento, com recurso a capitais estranhos como veremos a seguir.

As razões acima expostas é que tem entravado a solução do problema da casa, pois que, sendo um negócio que oferece sólidas garantias e, havendo capitais de um lado e, tomadores ávidos do outro, não se compreende, à primeira vista, que o mesmo já não esteja resolvido. A falta de sua sclução é devida, apenas, ao "modus faciendi" até hoje adotado.

Entre nós, várias tentativas têm sido feitas, já com as emprêsas de venda de terrenos e casas, à prestação, já com as sociedades de Economia Coletiva, já com cs financiamentos feitos pelos Institutos de Previdência; todavia, não lograram, êstes empreendimentos, o sucesso esperado.

Viram, as primeiras o seu campo de ação limitado, em conseqüência das dificuldades em obter, do candidato à casa, a percentagem relativa à entrada inicial e, também, pela inversão de grandes capitais, sem um sistema bancário que as auxiliasse; o mesmo sucedeu com as Sociedades de Eccnomia Coletiva, por falta de capitais estranhos à cooperativa e, quanto aos Institutos, em conseqüência do financiamento, cem por cento $(100 \%)$, a prazos longos, e do baixo padrão de vida de seus segurados.

Nos atuais financiamentos feitos pelas Autarquias, de um modo geral, não são satisfeitas as quatro condições acima apontadas garantidora do bom sucesso de um investimento.

De fato, dado o baixo padrão de vida existente entre nós, e falta de hábito do "pé-de-meia", poucos são aquêles que, previdentes, põem, de lado uma parte de seus lucros. É, aliás, um defeito que se poderia dizer, mesmo congênito; resulta da própria formação da nossa gente. Se lermos um pcuco da nossa história, verificaremos que os primeiros colonizadores aqui aportaram, em busca do ouro e das pedras preciosas, contando fazer fortuna, da ncite para o dia. As célebres bandeiras, são uma afirmação vigorosa do conceito acima. 
Se procurarmos saber porque muitas das nossas cidades estão, topogràficamente, mal situadas, constataremos que foram antigos registros, ou sejam: pôsto de polícia, para impedir o contrabando do ouro e de pedras preciosas.

Cum o correr do tempo, mudadas as condições de vida, já se vai notando uma transfcrmação benéfica no sentido de economia individual, que facilitada e, sobretudo, tendo uma finalidade, poderá ser de muito acrescida e passar a constituir hábito.

Os financiamentos como estão sendo feitos, atualmente, pelos Institutcs de Previdência, prejudicam, em geral, o segurado e sempre, o Instituto. Aos segurados, porque, - levados pelo desejo de ter sua casa, pødem sempre o máximo que a lei lhes faculta, apesar de saber que $45 \%$ de seus vencimentos serão empenhados, mensalmente, na liquidação da operação. Como os $55 \%$ restantes, não the permite viver, passa a se servir dos cmpréstimos individuais, das casas de prego, dos agiotas e, em grande número de casos, deixa, na primeira neccssidade, de pagar ao Instituto. Aí estão os inadimplimentos dos contratos de mútuo confirmando o que dizemcs. Observa-se, ainda, que no Sul do País é raro um pedido de empréstimo de $100 \%$; outro tanto, já se não pode dizer com relação ao Norte, o que se explica estudando a distribuição da renda nacional. Aos Institutos, porque financiado $100 \%$ da garantia oferecida, no caso de inadimplimento do contı ato de mútuo, quase sempre têm prejuízo, e, também, porque emprestando a longo prazo recebe em moeda, cujo poder aquisitivo é sempre menor.

Estudardo as hipotecas em face da desvalcrização da moeda, encontramos o seguinte na "Conjuntura Econômica":

".... Se tomarmos como ponto de partida o ano de 1912, verificaremos que o poder aquisitivo da nossa moeda vai decrescendo de tal modo, que a taxa média anual de depreciação é de $5.5 \%$ : Isto significa que: tctos os investimentos em moeda nacional produziram um rendimento real sòmente quando: $10^{\circ}$ ) a taxa nominal de rendimento, isto é, juros dividendos ou qualquer outra forma foi suficientemente elevada para compensar a perda do poder aquisitivo; $2 .^{\circ}$ ) o aumento do valor venal - no caso de imóveis ou títulos foi compensador."

No caso das hipotécas, resultante dos financiamentos, há um prejuízo real para o financiador.

De acôrdo ccm os estudos procedidos pela Funđação Getúlio Vargas, conclui-se que: "o rendimento real das hipotécas com 3 anos de duração - juros nominais de $12 \%$ - foi de $9.6 \%$ para as realizadas em $1937,4.2 \%$ para as iniciadas em 1942 e $11.7 \%$ para as referentes a 1947.

Os empréstimos com 10 anos de prazo, taxa nominal de $10 \%$, renderam, efetivamente, $2.1 \%$, desde que tenham principiado em 1932 e $7 \%$ se subscritas em 1937."

Quando os pagamentos são feitçs pela Tabela Price, melhora um pouco a rentabilidade, de vez que as "amortizações periódicas, constituídas de frações crescentes da dívida nominal primitiva, determinaram condições diversas, 
quanto ao coeficiente de compensação, que corresponde a depreciação do saldo, e, em conseqüência, também quanto a taxa aparente de jurcs."

"Na aplicação dos padrões de juros atualmente em vigor, às hipotecas amortizáveis em 20 ou mais anos, teria resultado uma remuneração insignificante ou nula do capital."

Com relação aos Institutsıs de Previdência Social, assim se expressa a Conjuntura Econômica, de fevereiro de 1951:

“... Os Institutos de Previdência Social empregam apreciável parte de suas disponibilidades em empréstimos a longo prazo, geralmente a juros de $6 \%$ ou $7 \%$, somas apenas suficientes para contrabalançar a depreciação. Não há o menor juro real."

Ainda mesmc que fôsse criado um seguro sôbre as hipotecas, como existe nos Estados Unidos, mesmo assim, só apresentariam elas segurança e exequibilidade, e não rentabilidade e finalidade social. Num país onde a moeda não é estável, dentro dos limites normais, não se pode pensar em hipctecas a longo prazo.

Estudando, ainda, a depreciação da nossa moeda, em São Paulo, diz a Divisão de Estatísticas e Documentação Social da Prefeitura de São Paulo que se tomarmos, em 1939, $c$ '́ndice do poder aquisitivo da moeda como sendo 100, em 1952 êste índice foi apenas 16.77 , o que equivale dizer que $\mathrm{Cr} \$$ $100.000,00$ só poderiam adquirir utilidades no valor de $\operatorname{Cr} \$ 16.770,00 \mathrm{em}$ 1952 .

As únicas instituições que podem sofrer a desvalorização da moeda, em hipotecas, são as Caixas Econômicas e as Companhias de Seguro e Capitalização. E isto porque, as Caixas Eccmômicas recebem depósitos populares e os devolvem pelo valor nominal, do mesmo modo, as Companhias de Seguro e Capitalização pagam os respectivos prêmios em moeda depreciada e pelo valur nominal, e não pagam juros sôbre o capital mutuado e, quando os pagam, como no caso da Capitalização, pagam-nos ainda pelo valor nominal.

A êste propósito, escreveu o Atuário J. LoIsel - "1'Epargne Colletive Imobilière formule de financement de la construction":

“.... A despeito destas diversas limitações destinadas a salvaguardar a segurança dos investimentos das companhias de seguro e capitalização, estamos pessoalmente convencidos que êste setor poderá dar uma contribuição das mais apreciáveis ao financiamento em fundos exteriores, das emprêsas de crédito mútuo e, ccnseqüentemente, aos problemas imobiliários, de capital importância, para cuja solução, elas contribuem."

Ainda sôbre 0 assunto, assim se expressa R.J.W. GRABBE - atuário inglês. "Os métodos de compras de casas na Inglaterra".

“.... O desenvolvimento dos empréstimos para construção, no sentido que acabo de indicar, é, atualmente, de considerável importância, porque responde à crítica de que êste gênero de operações só pode atender às classes relativamente prósperas da po- 
pulação. Nêste caso, as companhias de seguro podem prestar reais serviços para solução do problema, que, como foi demonstrado pelos relatórios apresentados a esta Assembléia, é quase universal, tanto mais que, como demonstram igualmente aqueles relatórios, o método inglês, das Buildings Societies, não poderá ser facilmente adaptável às necessidades de outras nações."

$\mathrm{O}$ assunto de financiamento, entre nós, ainda não foi devidamente estudado em face da nossa Conjuntura Econômica. Cabe a palavra aos Srs. Atuários. Uma coisa podemos adiantar, é que o que se tem feito até hojje não tem dado resultado e tem prejudicado a finalidade social, de vez que criou uma classe de privilegiados, que usufruem lucros a custa da coletividade, e tem aumentado o número dos descontentes.

E' mais útil ao segurado e ao Instituto, a aquisição, por êste, de terreno, do que o financiamento a $100 \%$.

Para confirmação, citemos, entre muitos, o caso do terreno adquirido pelo IAPC, à rua Goiás, em 1939, por Cr\$310.000,00 (trezentos e dez mil cruzeiros). Em 1949, foi feita uma oferta de $\operatorname{Cr} \$ 1.800 .000,00$ (hum milhão e oitocentos mil cruzeiros), pelo mesmo, valor êste fixado por avaliador da Bôlsa de Imóveis).

Mesmo calculando os juros de $12 \%$, sôbre o seu valor, teríamos um lucro de $\mathrm{Cr} \$ 949.862,40$ (novecentc's e quarenta e nove mil, oitocentos e sessenta e dois cruzeiros e quarenta centavos).

Se o Instituto tivesse financiado uma construção daquêle valor, ao fim de 16 anos, e, ainda mesmo aos juros de $12 \%$, receberia o seu capital e mais $\mathrm{Cr} \$ 640.137,60$ de jur's, ou em -outras palavras, teria um prejuízo de $\mathrm{Cr} \$$ $949.862,40$ (novecentos e quarenta e, nove mil, oitocentos e sessenta e dois cruzeiros e quarenta centavos).

De 1939 a 1946, o Instituto de Aposentadoria e Pensões dos Comerciários arquiriu, no Distrito Federal, terrenos no valcr de CrS 58.275.654,00.

Em 1950, procedemos a uma reavaliação dêstes terrenos e, tomando para valores unitários cs da Prefeitura do Distrito Federal, encontramos um valor de Cr $\$ 384.907 .857,10$ ou seja um benefício de $564 \%$ !

Com o fim de procurar ajustar os salários ao custo da vida, adotaram alguns governos medidas com relação aos aluguéis, medidas estas que, no fundo, tendem para a socialização de propriedade e trazem, como conseqüência, o afugentamento dos capitais. Ninguém mais constrói para alugar; todos constroem para vender, encarecendo a prcpriedade.

Com relação à lei do inquilinato, observou-se no Distrito Federal que, em 1952, apenas $47.2 \%$ dos inquilinos se valiam dos benefícios da lei, os restantes $52.7 \%$, já estavam pagando aluguéis novos ou então procurando comprar casa. 
Diz o professor L. Grabbe, da Universidade da Columbia, encarregado das Pesquisas sôbre Urbanismo e Habitação, num artigo intitulado "As repercurções da regulamentação dos aluguéis nos Estados Unidos"!

“.... De qualquer modo, $c$ contrôle dos aluguéis parece ter contribuído para a diminuição de casas para locações ao mesmo tempo também diminuída a construção de habitações para locação, como vimos acima."

Além de entravar o ritmc das construções, também contribui a lei do inquilinato para o perecimento do patrimônio imobiliário, que não é individual e sim nacional - de fato não produzindo o imóvel renda, não há interêsse em conservá-lo. Criam-se assim as casas de cômodos (ccritiços).

A êste propósito escreveu Paul VoIsin - "Une Politique de L'Habitat:" “.... Não é, aliás, menos escandaloso ver que, dentro de certos limites, mais de um proprietário neglicenciando seu imóvel, maior renda obtém e que se o prédio, durante muito tempo, constituiu uma mina de ouro, não foi senão para c's próprios donos de casas de cômodos."

A lei do Inquilinato também cria a indústria das sublocações. Tempo houve em que a maior aspiração do indivíduo era construir casa para alugar, pensava, assim, ao morrer, deixar sua família a cobert 0 das necessidades; a lei do inquilinato, justamente com a depreciação da moeda, tornou aquêle desejo uma quimera.

A França, vendo parecer seu patrimônio imobiliário, promulgou a lei de setembro de 1948, que permite o aumento d's aluguéis escalonados no tempo, e de acôrdo com as condições de habitabilidade do imóvel.

No Rio de Janeiro, as novas locações foram realizadas sem nenhum contrôle e apresentaram, em 1950, um índice médio de aumento de $665 \%$ sôbre o padrão de 1940 .

E' inegável que o direito de prepriedade sofreu algumas restrições e, como escreveu P. Bernard, "tôda a propriedade é um complexo de direitos individuais e de função social" e que "as diversas formas de propriedades diferem uma das outras pela proporção respectiva do direito individual e da função social que entram na composição de cada uma."

A nossa legislação só leva em conta a função social da propriedade em se tratando de propriedade loja. A simples extensão da lei 24.150 , de 20 de abril de 1924, à propriedade moradia, daria um grande incentivo às construções, de vez que garantiria um rendimento razoável do capital invertido.

Para elucidar, vem de molde transcrever o que disse a Conjuntura Econômica, apreciando a lei do inquilinato de $1 .^{\circ}$ de janeiro de 1951 , que liberou os aluguéis das novas construções:

“.... Tudo leva a crer, no entanto, que o número de "Habitese", para residências, concedidos em 1951 , tenha sido quase $10 \%$ maior do que no ano precedente, ainda inferior ac nível do ano 
base de 1946. Assim é que, em 1951 obtiveram "habite-se" 4.285 residências, até setembro, contra 3390 em período idêntico de 1950.

Com respeito a casas populares o aumento foi extraordinàrio; da ordem de $50 \%$, em relação a 1950 , fazendo saltar o índice de 146 para 226."

Torna-se, pois, necessário encontrar a solução do problema financiando a juros baixos e a prazos curtos, bastando para isto obter o auto-financiamento da construção, pelos próprios interessados, 0 que se consegue fàcilmente, com as cooperativas de construção tão bem organizadas na Inglaterra, onde tiveram início em 1781 .

Referindo-se às cooperativas de construção, diz SAMUEL PARKER, op . cit .:

“... "As Buildings Societies" criaram na Inglaterra uma mística de habitação familiar, uma mística de "Lar". De um modo geral, elas foram dirigidas por homens tendo um ideial muito elevado e espírito de desinterêsse. Elas tiveram, no conjunto, um êxito extraordinário.

Que julguemcs por alguns dados:

O "Haver", no balanço das Buildings Societies, era no fim de 1936, de mais de 98 milhões de francos.

Mais de 2.800 .000 casas foram construídas, de 1920 a 1930 , graças à sua intervenção.

Em 1935, 298.079 casas, foram construídas com a sua assistência e, sòmente 1.139 , com a do Estado.

Em 1936, 286.202 casas foram construídas com a assistência das "Buildings Societies" e, sòmente 222 casas, com a assistência do Estado.

Em período de crise mundial, em 1936, as "Buildings Societies", permitiram a construção de 146.000 casas e deram trabalho a 750.000 operários.

As "Buildings Societies" criaram na Inglaterra de um modo absoluto, uma classe média. Le 1920 a 1939, 2.800.000 casais puderam obter uma habitação graças aos auxílios das "Buildings Societies".

Eles teriam ficado, na sua maicria, simples locatários se as "Buildings Societies" não existissem. Êstes 2.800 .000 casais, que representam de 9 a 10 milhões de pessoas cessaram de ser proletários; tornaram-se, agora, pequenos proprietários.

Estão estabilizados. Sua mentalidade de hoje, em diante, é completamente diferente. De uma atitude reivindicadora, êles passaram ao estado de homens e mulheres conscientes de sua dignidade.

Eles têm uma casa, um tetc. Êles não são mais párias. 
Sir HaROld Belliman declarou com justa razão: "as Buildings Societies" fizeram "The silent Revolution".

Estas sociedades fundadas na Inglaterra, no século 18, espa1haram-se pelo mundo. Fundou-se, em 1831, a "Oxford Prevident Building Association of Frankfort, nos Estados Unidos. Em 1880, o govêrno Francês mandou estudar o assunto nos Estados Unidos; depois, na Alemanha, fundaram-se as Baunparkassen, etc."

HAROLD Bellman, in "The Building Societies Mcrement", assim definiu as "Buildings Societies":

“. . . Uma sociedade - construtora é o conjunto de financiadores e mutuários, operando dentro de normas estabelecidas e controladas pelo Govêrno, a fim de promover $\mathrm{c}_{3}$ ideais de economia e Lar próprio. Os capitalistas, que podem ser, associados acionistas, - ou simplesmente depositantes, fornecem fundos, com os quais são feitos os empréstimc's para a compra da casa.

A diferença entre a taxa de juros recebida do mutuário prestamista e a que é paga ao associado depositante, constitui margem, que habilita a Sociedade a fazer face às despesas de administração, cifra muito modesta na maioria dos casos, bem como a formar e manter adequado fundo de reserva.

As bases de operação de uma sociedade de construção incorporada e permanente, assemelha-se à de um Banco, do qual, entretanto, diferem na constituição e objetivo, sendo a sociedade essencialmente cooperativista ou mútua, em princípio, e existindo, ùnicamente, para benefício de seus sócios."

Verificou-se, depois, ser grande o prazo para a obtenção do empréstimo, tendo os inglêses chegado à conclusão de que o único meio era o financiamento cbtido com recursos alheios ao círculo dos operadores, conseguindo, mesmo, as caixas inglêsas abolir o prazo de entrega logo que os mutuários completavam uma determinada entrada inicial de, mais ou menos $10 \%$.

Sir Austin Chamberlain, em fins de 1935, por ocasião de uma assembléia Geral, da "Halifax Building Societies" (a maior caixa construtora do Universo), com depósitćs no valor de 10 bilhões de cruzeiros, e 873.000 associados, pronunciou um longo discurso sôbre a significação do movimento pró "Lar Próprio", onde dizia:

"... Minha cidade natal é Birminham, onde foi fundada a primeira "Caixa Construtora" (no fim do $18^{\circ}$ século). O atual desenvolvimento é extraordinàriamente diferente daquela primeira experiência. Como nãc ficariam surpreendidos os fundadores dessa caixa, se thes fôsse dado ver o desenvolvimento da economia pró "Lar Próprio", na Inglaterra e no mundo inteiro!

Estou ligado a muitas iniciativas de ordem pública do país, mas, nenhuma merece tanto a minha consideração $\odot$ aprêço ccmo o grande movimento de famílias que pugnam pela aquisição de um 
patrimônio e de uma casa própria, por meio da economia coletiva! Uma iniciativa originàriamente pequena, modesta e desconhecida, tomou um incremento formidável - haja visto a "Halifax Buiding Society", cujo movimento, nos últimos anos, (digo 20 anos), multiplicou-se 25 vezes! Nunca me foi dado observar semelhante desenvolvimento em empreendimento de outra natureza!"

Em tôdas as modificações havidas no sistema, - quer nas organizações americanas, alemãs ou francesas - , permaneceu sempre intato o princípic inglês: "servir de intermediário entre as pessoas que desejam uma aplicação segura e rendosa do seu dinheiro e aquêles que procuram um empréstimo para construir seu Lar".

Na sua obra, "la Tecnique Moderne du Crédit Mutuel", assim descreve JEAN AntoIne Roqueplo, as "Buildings-Societies", ou Sociedades de Economia Coletiva:

".... Os criadc:es das Sociedades de Crédito Mútuo partiram de uma idéia simples e sâ; reunir, num fundo comum, a economia de um certo número de pessoas, na medida da sua criação, e distribuir esta mesma economia, de um modo contínuo, sob a forma de empréstimos. O princípio é o seguinte: pequenas econcmias, disseminadas, são improdutivas, enquanto que reunidas em porções mais importantes permitem aos beneficiários fazê-la frutificar.

Coletar a economia e distribuí-la, é a finalidade de todo organismo de crédito, não havendc; nesta operação, nenhuma característica que distingua o Crédito Mútua; mas, a característica original desta instituição e que justifica êste adjetivo, é que o beneficiário em questão não pode ser escolhido senão entre os prestamistas, que contribuiram para o fundo comum. Cada prestamista não contribui para a alimentação dêste fundo senão, precisamente, com o fim de ser, um dia, beneficiado por um crédito."

Estas ccoperativas entre nós devem ser constituíclas por capitais municipais, fornecidos pelo Comércio e Indústrias, locais. O nosso problema é "municipal", e enquanto da Capital Federal pensarmos em resolvê-lo, os resultados serão nulos como até aqui.

As cocperativas de construção, que tão bons resultados têm dado na Europa, além de permitir obter do investimento, os rendimentos esperados, têm a vantagem de "educar" a nossa gente, o que constitui a base para a solução do Problema da Habitação, bem como introduzir hábitos de eccnomia, obrigando a cada um, a esforçar-se para obter sua casa.

Em trabalho publicado na Revista "Cooperativa da União Pan Americana", assim se expressa o Prof. Francisco Luiz Jimenez:

“... O movimento cooperativo é o melhor sistema econômico social para garantir a Democracia no mundo, porque está baseado em princípios essencialmente humanos, que afirmam a personalidade do indivíduo e conservam, para todos, as liberdades essenciais a uma vida amena e segura. 
“... O cooperativismo é o melhor meio para resolver o angustioso problema da habitação porque prescinde da idéia de lucro, obedece à planificação técnica e favorece, em cada casc particular, à realização de normas precisas para dar a cada um a sua Casa."

As cooperativas não pcdem prescindir de auxílio financeiro externo, para o seu perfeito funcionamento, e, sobretudo, para diminuir o prazo de espera para obtensão do crédito, auxílio êste que seria dado por um Fundo Social; adiante referido.

Além do mais, como bem acentuou o atuário J. LoISEL - "As Sociedades de Economia Coletiva ou Cooperativas de Habitação": a contribuição cooperativa permite uma economia de $50 \%$ do capital destinado ao financiamento.

“.... Num país onde a reconstrução necessita a chamada de fundos consideráveis, a economia mínima de $50 \%$, que é a consequiência da contribuição cooperativa, não pode senão acentuar tôda a impurtáncia que representa esta solução."

Estas Sociedades de Crédito Mútuo, além da segura inversão de capitais, - de vez que são sociedades de Crédito Real —, fomentam, ainda, a economia, habituando os indivícuos a "poupar", continuadamente, com a finalidade de obter sua casa.

A segurança é tanta que, durante a crise financeira de 1931, nc's Estados Unidos, sôbre 22.071 bancos, 1.561 faliram, (seja 7\%), enquanto, no mesmo ano, sôbre 11.442 cooperativas para construções de casas, não houve senão 126 falências (seja 1.1\%). Ainda apresentam a vantagem de poderem, os financiamentos, ser feitos a juros muito baixos, apenas o suficiente para pagar a administraçãc, de vez que o capital é dos próprios mutuários, que não procuram lucros. A distribuição dos financiamentos se fará, segundo as entradas feitas e o tempo decorrido, não cabendo, nêtse trabalho, o estudo da técnica do seu funcionamento; é nossa intenção, apenas, mostrar a sclução a ser adotada.

Organizadas as cooperativas de construção de casas, e criado o Fundo Social da Habitação, passarão os Departamentos de Aplicação de Fundos des IAP a agirem de outro modo, isto é, contribuindo para o fundo social e administrando as respectivas cooperativas.

Os financiamentc's suplementares serão feitos a prazo curtos e juros comerciais.

No memorando apresentado à Comissão de Estudos Econômicos da Europa, pela Aliança Cooperativa Internacional, lê-se:

“.... As sociedades cooperativas de Habitação, constituiram sempre um meio eficaz para combater a carência de Habitação, como a existente desde o fim da guerra. Depois do primeiro conflito mundial, já um grande número destas sociedades se criou, na maior parte dis países da Europa para solucionar o problema da Habitação, conseqüente ou agravado pelo período das hostilidades. 
O seu desenvolvimento foi rápido e elas representaram um papel considerável no que concerne a construção de novas habitações, pois que, segundo os países ou localidades, elas participaram numa percentagem de 30 a $40 \%$, naquele propósito.

A questão principal que as cooperativas de habitação devem resolver para preencher sua finalidade é a do financiamento."

Como a distribuição dos créditos se fará periòdicamente, de acôrdo $\mathrm{ccm}$ os depósitos mensais de cada prestamista, quanto maior fôr o montante dos depósitos, tanto maior será o número de contemplados.

Aquêles que já tenham um depósito correspondente a uma determinada percentagem de financiamento pretendido poderão requerer ao seu Instituto, o financiamento suplementar.

Este financiamento suplementar encurtará o prazo de espera por parte do prestamista, apressando a distribuição o que the permitirá fazer sua casa mais ràpidamente. A partir do momento em que ccupa sua casa, suas prestações serão maiores e, conseqüentemente, aumentará o montante dos depósitos .

Os financiamentos suplementares, feitos, como foi dito, a juros comerciais e prazos curtçs, garantirão aos Institutos uma constante renovação dos seus capitais, não permitindo que a depreciação da moeda os afete profundamente, como presentemente acontece, facilitando, também, a atender a um maior número de segurados e mesmo não segurados. Não estando compreendida dentro das finalidades dos Institutos o financiamento da casa própria, senão como uma aplicação de capitais, o sistema ora preconizado permitirá que os capitais da Previdência Social sejam aplicados normalmente, como os de qualquer Instituição bancária.

Vem de molde aqui esclarecer, mais uma vez, que a finalidade dos Institutos è a de dar aos seus asscciados a Aposentadoria; e a Pensão, às suas famílias. A aplicação de seus capitais em hipotecas é feita, principalmente, para atender aquelas duas finalidades principais.

A organização das cooperativas, para a construção de casas, poderá ser generalizada, permitindo os financiamentos em geral, financiamento êstes, que tanto contribuiram para o nosso desenvolvimento.

E' necessário esclarecer que os capitais da Previdência Social não são de propriedade privada dos seus segurados; todos nós contribuimos para a sua formação; uns, direta; outr's's, indiretamente; êles pertencem à coletividade, é justo, pois, que voltem ao seu seio, na forma de financiamentos para a construção de habitações, sejam elas isoladas ou coletivas, pertençam ou não aos seus segurados.

Os financiamentos feitçs indistintamente, como mera aplicação de capital, promoverão o desenvolvimento das construções, criarão a riqueza, fazendo-a circular, aumentarão as áreas locáveis, barateando as respectivas locações, darão trabalho, evitando o "chomage", contribuirãc, em suma, para o estabelecimento da Paz Social. 
Para se conseguir esta finalidade, torna-se indispensável a revisão de nossa Legislação Social, dentro de um espírito liberal, abandonando seu aspecto tutelar e que, conjuntamente, seja revista a Legislaçãc de Seguros, de modo a permitir a criação do seguro de hipotecas, que tão bons resultados deram nos Estados Unidos.

O financiamento deve ser concedido tendo em vista, apenas, a garantia oferecida, poucc importando a qualidade do indivíduo, sua idade, suas possibilidade econômicas, seu estado civil; esta garantia não deve ser onerada, como atualmente, devendo ser facultado ao segurado, o direito de negociá-la livremente.

O ônus criado com a inalienabilidade do imóvel, é a causa do seu perecimento, pcrque na maioria dos casos, o segurado depois de aposentado, não dispõe de recursos para conservá-lo.

Exposto assim o aspecto econômico do problema e, preconizada sua solução, passemos a examinar seu aspecto técnico.

\section{SUMMARY}

1. Investments on housing have always been among the most productive, being, historically. the privilege of the wealthy.

2. Characteristics of a sound investment: (1) good wartant; (2) rentability; feasibility; (4) social purpose. The four characteristics discussed.

3. Several unsuccessful attempts to solve the housing problem for all. Criticism of the methods that have been utilized in Brazil up to the present.

4. Illustrations of practical measures undertaken by several Brazilian agencies of social security as regards the housing prob!em; their ir criticism.

5. Reference to the "building societies" of Great Britain: their policies and the ir influence on the solving of the housing problem for large number of people of the midle classes.

6. Positive suggestions of the Author in favour of the institution of a cooperative system on a municipal basis, capable of solving the housing problem in Brazil. Revision of our social legislation as a prerequisitive of such initiative.

A juridicidade da administração pública é fruto do liberalismo político. Os direitos do homem geram os deveres do Estado. Nos regimes absolutos, o administrador - veículo da vontade do soberano - é, como êste, irresponsável. A administração é, apenas, uma técnica a serviço de privilégios de nascimento. O Estado de Direito, ao contrário, submete o Poder ao domínio da Lei: a atividade arbitrária se transforma em atividade jurídica.

CaIo TÁcrto, Evolução Histórica do Direito Administrativo (Notas de Aula) "R.S.P.", março de 1955. 